\title{
INFLUÊNCIA DA ESCOLHA DO PRODUTO-BASE DO MÉTODO UNIDADES DE ESFORÇO DE PRODUÇÃO (UEP) NO CUSTO UNITÁRIO DE TRANSFORMAÇÃO
}

\author{
INFLUENCE OF THE CHOICE OF BASE PRODUCT OF THE PRODUCTION EFFORT UNITS (PEU) METHOD ON \\ THE UNIT COST OF PROCESSING
}

Silvete Moterle ${ }^{1}$

Rodney Wernke ${ }^{2}$

Antonio Zanin ${ }^{3}$
${ }^{1}$ Mestre em Ciências Contábeis e Administração/Unochapecó Instituto Federal de Educação, Ciência e Tecnologia Catarinense silvete@unochapeco.edu.br

${ }^{2}$ Doutor em Engenharia de Produção/UFSC Sem vínculo institucional rodneywernke1@hotmail.com

${ }^{3}$ Doutor em Engenharia de Produção/UFRGS PPGCCA/Unochapecó zanin@unochapeco.edu.br
Resumo: O artigo objetivou analisar se a escolha do produto-base do método UEP interfere no valor monetário do custo unitário dos produtos. Para essa finalidade foi utilizada metodologia classificável como descritiva, qualitativa e no formato de estudo de caso. Realizado com dados reais do setor de salsicharia de frigorífico, os cálculos efetuados permitiram concluir que, independentemente do produto-base escolhido, não há alteração no valor final alocado a cada produto em termos de custo unitário de transformação. Com isso, a contribuição principal do estudo consiste em comprovar, matematicamente, que não cabe considerar um aspecto negativo a ausência de critério(s) específico(s) para definir qual item deve ser escolhido como produto-base, porque isso não altera efetivamente o valor atribuído como custo unitário de transformação. Mesmo tratando-se de estudo de caso, com base nos cálculos apresentados é cabível dessumir que tal experimento pode ser replicado em outros tipos ou portes de empresas fabris.

Palavras-chave: Método UEP. Escolha do produto-base. Estudo de caso.

Abstract: The article aimed to analysis if the choice of base product of the PEU method interferes in the monetary value of the unit cost of the products. For this purpose, the methodology was used as descriptive, qualitative and case study format. Based on actual data from the refrigerator sausage sector, the calculations made allow us to conclude that, regardless of the base product chosen, there is no change in the final value allocated to each product in terms of the unit cost of processing. Thus, the main contribution of the study is to prove, mathematically, that it is not possible to consider a negative aspect to be the absence of specific criterion (s) to define which item should be chosen as the base product, since this does not effectively change the value assigned as the unit cost of processing. Even if it is a case study, based on the calculations presented, it is reasonable to assume that such an experiment can be replicated in other types or sizes of manufacturing companies.

Keywords: PEU Method. Choice of base product. Case study. 
Moterle, S., Wernke, R., \& Zanin, A. (2020, out./dez.). Influência da escolha do produto-base do método Unidades de Esforço de Produção (UEP) no custo unitário de transformação

\section{Introdução}

A determinação dos custos de produção é essencial em todas as organizações fabris. Com o acirramento da concorrência a necessidade de racionalização dos recursos é cada vez mais importante para as empresas se manterem competitivas no mercado e vislumbrarem um bom desempenho financeiro. Nesse rumo, Lunkes, Luiz, Gasparetto e Schnorrenberger (2015) defendem que as informações referentes aos custos de produção são relevantes para a tomada de decisão acertada pelos gestores. Entretanto, o gerenciamento de custos nem sempre é tarefa fácil, pois exige esforços contínuos e alinhamento dos objetivos às estratégias empresariais (Lopes \& Beuren, 2017).

A fim de possibilitar esse gerenciamento, a literatura contemporânea apresenta diversos métodos de custeio, os quais devem ser estudados caso a caso para identificar o que melhor se adapta às necessidades organizacionais, a saber: custeio por absorção, custeio pleno ou BAB (Betriebsabrechnungsbogen), custeio variável, custeio direto, ABC (Custeio Baseado em Atividades) ou TDABC (Time-driven Activity-based Costing) e UEP (Unidade de Esforço de Produção), conforme Lunkes et al. (2015).

Quanto aos métodos de custeio que utilizam modelos com base em equivalência, além do UEP, o mais conhecido e o com mais tempo de aplicação é o método Unité de Valeur Ajouteé (UVA), bastante difundido na França e na Grã-Bretanha (Gervais \& Levant, 2007). Contudo, diversos autores mencionam que este tipo de método apresenta algumas inconsistências ou incertezas, como a necessidade de atualizações constantes e subjetividade na escolha do produto-base (Pereira, 2015; Levant \& Zimnovitch, 2013; De La Villarmois \& Levant, 2011; Meyssonnier, 2003; Gervais \& Levant, 2007; Gervais, 2009; Malaquias, Giachero, Costa, \& Lemes, 2007). Por outro lado, Wernke e Junges (2017) mencionaram que a escolha do produto-base não influenciaria o valor do custo total unitário dos produtos. Porém, não detalharam numericamente como chegaram a essa conclusão e nem evidenciaram algum cálculo para fundamentar tal opinião.

Assim, considerando as divergências encontradas na literatura, discussões acerca dessas inconsistências ou incertezas são necessárias para elucidação dos benefícios ou desvantagens que cercam o método de custeio UEP, a fim de aferir a confiabilidade das informações geradas para fundamentar a tomada de decisão dos gestores que usam esta forma de custeamento.

Nesse sentido, o foco do presente estudo centra-se na escolha do produto-base e pretende responder à seguinte questão: qual a influência da escolha do produto-base do método UEP no valor monetário do custo unitário dos produtos? Para esse propósito foi definido como objetivo de pesquisa analisar se a escolha do produto-base do método UEP interfere no valor monetário do custo unitário dos produtos.

Um estudo com esse enfoque se justifica pela relevância do método de custeio UEP, principalmente na região Sul do Brasil, onde o modelo é mais disseminado (Ferrari \& Reis, 2016). Argumenta-se, ainda, que em consulta às bases de dados Web Of Science, Spell e Google Acadêmico 
não foram encontrados estudos com o mesmo enfoque, vislumbrando-se assim uma lacuna de pesquisa a ser mais explorada.

\section{Revisão da literatura}

As próximas seções descrevem os principais aspectos do método priorizado neste estudo, bem como estudos anteriores que abordaram esta forma de custeamento.

\subsection{0 método UEP}

Precedido pela Unidade GP e método UP, o método das Unidades de Esforço de Produção (UEP), ou Unité de Valeur Ajouteé (UVA) como é conhecido na França, foi desenvolvido na década de 1940 pelo Francês Georges Perrin, que deu ao método o nome de suas iniciais - GP (De La Villarmois \& Levant, 2011). A ideia central de Georges Perrin era possibilitar, por meio de uma única unidade de medida, mensurar os custos de toda a produção de uma fábrica, por mais diversificada que fosse (Allora \& Allora, 1995).

No início dos anos 1960, o engenheiro italiano Franz Allora veio ao Brasil e passou a divulgar no país o método UP, que posteriormente passou a ser chamado Método UEP. Em 1978 Franz Allora criou, em Blumenau (SC), uma empresa de consultoria destinada a implementar o novo método de cálculo de custos nas indústrias da região (Bornia, 2009; Allora \& Gantzel, 1996).

Na França, com o aprimoramento da técnica pela empresa de consultoria Les Ingénieurs Associés (LIA), sob a direção de Jean Fiévez e Robert Zaya, em 1977 o método foi renomeado, passando a ser denominado método Unité de Production ou Production Unidad (UP). Em 1995, o método expandiu seu conceito inicial que era focado apenas na produção e passou a analisar grande parte dos custos empresariais, quando começou a ser chamado de Unité de Valeur Ajouteé - UVA (De La Villarmois \& Levant, 2011).

Quanto à sua concepção, o método UEP consiste na determinação de uma unidade de medida comum (a UEP) para o cálculo dos custos de todos os produtos fabricados pela empresa, simplificando o processo de controle de gestão e possibilitando a identificação dos custos por produto. Isso é especialmente interessante para o controle e o cálculo dos custos de produção em indústrias com um mix grande de produtos porque proporciona uma simplificação dos cálculos devido à utilização de uma única unidade de medida (Bornia, 2009).

Quanto à implementação do método UEP, de acordo com Wernke (2019), Wernke, Santos, Junges e Scheren (2018), Guimarães Filho, Bristot, Marques, Feil e Colombo (2016), Pereira (2015) e Souza e Diehl (2009), esta ocorre em seis fases: (1) divisão da fábrica em postos operativos; (2) determinação do custo/hora por posto operativo; (3) escolha do produto-base; (4) cálculo do valor da UEP/hora de cada posto operativo; (5) definição dos equivalentes dos produtos em UEPs e (6) cálculo 
Moterle, S., Wernke, R., \& Zanin, A. (2020, out./dez.). Influência da escolha do produto-base do método Unidades de Esforço de Produção (UEP) no custo unitário de transformação

da produção total da fábrica no período em termos de UEPs. Depois disso é que pode ser apurado o custo de transformação da matéria-prima em produto pronto.

Quanto à divisão da fábrica em postos operativos, esta etapa consiste em identificar os conjuntos operativos que apresentam características semelhantes para todos os produtos que necessitam da passagem naquele posto durante o seu processo de transformação, diferenciando-se uns dos outros apenas pelo tempo de duração de sua passagem. Por outro lado, a determinação do custo/hora, ou foto-índice, evidencia o índice numérico que determina o valor do custo por hora de cada posto operativo. Quanto à escolha do produto-base, este pode ser um dos produtos fabricados na empresa ou um fictício. Porém, alguns autores recomendam que este seja o produto com fabricação mais complexa ou que possua maior representatividade na linha de produção da empresa (Wernke, 2019; Souza \& Diehl, 2009).

No que se refere aos seus fundamentos teóricos, Allora e Oliveira (2010) argumentam que o método UEP está assentado em três princípios:

a) Princípio da Constância das Relações: quaisquer que sejam as variações dos preços unitários, os esforços de produção desenvolvidos pelas operações elementares de trabalho em uma fábrica são interligados entre si por relações constantes no tempo. Este princípio também é considerado no UVA, onde é conhecido como "Princípio das Relações Ocultas" (Gervais \& Levant, 2007).

b) Princípio das Estratificações: o grau de exatidão dos resultados é essencialmente dependente do grau de diferenciação de cada nova estratificação de despesas em relação às precedentes.

c) Princípio do Valor Agregado: este princípio determina que o lucro da empresa limita-se ao valor monetário pelo trabalho realizado, ou seja, o esforço para a transformação.

No que tange aos benefícios proporcionados, o método UEP apresenta diversas funcionalidades que permitem mensurar o esforço de produção de cada etapa de fabricação dos produtos até a sua totalidade (Allora \& Oliveira, 2010). Na mesma direção, mas referindo-se ao UVA (que é muito semelhante ao UEP), Gervais e Levant (2007) aduzem que este diferencia-se dos demais devido à possibilidade de apuração dos custos individuais dos produtos, o que pode auxiliar na tomada de decisões acerca da interrupção da produção de itens que não agregam valor à empresa.

Nesse rumo, Bornia (2009), Souza e Diehl (2009), Allora e Oliveira (2010), Wernke, Junges e Cláudio (2012), Wernke, Junges e Lembeck (2015) e Wernke e Junges (2017b) defendem que, além de possibilitar o cálculo de transformação dos produtos (de forma unitária e total), o método UEP também pode ser utilizado para avaliar a lucratividade fabril, determinar os preços de vendas dos produtos, mensurar a produção do período, identificar a capacidade de produção, comparar processos, examinar a necessidade de novos investimentos em equipamentos e/ou pessoal, avaliar a eficácia fabril relacionada às horas-extras etc. 
Contudo, existem algumas limitações que são atribuídas ao método UEP. A respeito disso, Bornia (2009) relata que o UEP centra atenções somente na transformação dos produtos e, com isso, as despesas de estrutura não são contempladas. O descaso com essas despesas pode ser considerado um problema, visto que estas vêm aumentando ao longo dos anos e merecem ser analisadas detalhadamente para sua racionalização. Por sua vez, Martins e Rocha (2010) também se manifestam nesse rumo quando citam que esse método prioriza apenas os custos de transformação, desdenhando do custo de overhead (logística de suprimento, controle de qualidade etc.).

Além disso, a literatura contábil atribui aos sistemas de cálculo de custos diversas inconsistências. Nesse rumo, como possibilidades de erros podem ser citados os equívocos de medição, de especificação e de agregação (Datar \& Gupta, 1994) ou erros de subutilização da capacidade produtiva (Kaplan \& Anderson, 2004). Sobre esses fatos, Gervais e Levant (2007) avaliam que atualizações de dados (tempos de processamento, volumes produzidos etc.) quando da ocorrência de mudanças significativas são essenciais para reduzir a possibilidade de uma gama de erros possíveis na utilização dos métodos de custeio.

Contudo, permanecem controvérsias a respeito da subjetividade ou não do método UEP pela escolha do produto-base, o que é abordado na próxima seção.

\subsection{A escolha do produto-base}

Uma das etapas da implantação do método de custeio das UEP é a escolha do produto-base, que serve para definir a unidade de medida padrão a ser utilizada para apuração dos custos dos produtos da unidade fabril (Bornia, 2009; Souza \& Diehl, 2009; Allora \& Oliveira, 2010).

No entender de Allora e Allora (1995, p. 15), a UEP "é um elemento bem definido dentro da fábrica, fixado de uma vez por todas e estável no tempo". Asseveram, ainda, que é por meio da UEP que são medidos todos os esforços da atividade fabril e que o cálculo utilizado para obtenção do valor da UEP requer a seleção de um produto do mix fabricado para ser o produto-base.

Nesse sentido, para escolha do produto-base tem sido recomendado que este seja um item que percorra o maior número possível de postos operativos ou aquele de maior representatividade para a empresa (Wernke, 2019; Malaquias et al., 2007; Bornia, 2009; Souza \& Diehl, 2009; Allora \& Oliveira, 2010).

Contudo, por não haver critérios definidos especificamente para a escolha ou determinação do produto-base, Malaquias et al. (2007) e Pereira (2015) atribuem um nível de subjetividade a esta etapa do processo de implantação do método UEP. Alegam que a falta de uma regra a respeito faz com que a escolha do produto-base ocorra com a parcialidade do consultor ou do gestor que está efetuando a implantação do método.

Meyssonnier (2003), ao apresentar alguns problemas relativos ao método UVA (que se aplica aos métodos que trabalham com equivalência de produtos, como é o caso do UEP), comenta que a 
Moterle, S., Wernke, R., \& Zanin, A. (2020, out./dez.). Influência da escolha do produto-base do método Unidades de Esforço de Produção (UEP) no custo unitário de transformação

escolha do produto-base é questionável. Nesse rumo, Levant e Zimnovitch (2013), De La Villarmois e Levant (2011), Gervais (2009), Gervais e Levant (2007) e Meyssonnier (2003) também atribuem incertezas à determinação do produto-base nos métodos de custeio baseados em equivalência.

No entanto, Wernke e Junges (2017, p.146) argumentam que a escolha de " $X$ " ou " $Y$ " como produto-base "não tem influência no valor dos custos indiretos unitários que são atribuídos aos componentes do mix produzido". Limitado a esta observação (talvez por não ser o foco da pesquisa), o referido estudo não apresenta cálculos para fundamentar tal conclusão e não traz mais detalhes a respeito dessa afirmação.

Assim, como outras publicações com opinião assemelhada à de Wernke e Junges (2017) não foram encontradas, nesta pesquisa foi priorizado esclarecer a respeito, conforme discutido a partir da seção 4 deste artigo.

\subsection{Estudos anteriores assemelhados}

Com o fito de conhecer as publicações com foco assemelhado foram efetuadas pesquisas online nas bases de dados Web of Science, Google Acadêmico e Spell, onde não foram encontrados estudos com o mesmo objetivo proposto neste trabalho. Para tanto, foram adotados termos de buscas equivalentes a "custos+UP", "UEP", "custos+UEP", "UVA", "coûts+UVA" e "méthode+UVA", mas não foram identificados artigos que atendessem aos critérios de busca.

Entretanto, foi possível acessar diversos estudos que mencionam a subjetividade da escolha do produto-base no método UEP e que analisaram outros fatores no referido método. Então, por se relacionar com o objetivo desta pesquisa, alguns estudos considerados mais relevantes na elaboração desta pesquisa são comentados na sequência.

De La Villarmois e Levant (2005) buscaram apresentar casos de empresas que haviam adotado o método UVA para a determinação do custo fabril nos dez anos anteriores àquele estudo. A principal vantagem observada pelos autores foi a possibilidade de pequenas empresas obterem uma gama de informações detalhadas sobre os custos de fabricação dos produtos sem dispêndios elevados para a implantação e manutenção do método. Contudo, ressalvam que a abordagem dada ao estudo realizado não permitiu avaliar as incertezas atribuídas ao método quanto à escolha do produto-base e à estabilidade das constantes ocultas.

Buscando identificar maneiras de garantir a homogeneidade do método UVA e utilizando um estudo de caso múltiplo, Gervais e Levant (2007) averiguaram a validade do Princípio das Constantes Ocultas e relataram diversos possíveis erros no método UVA. Nas conclusões oriundas apontaram a necessidade de atualizações periódicas para manutenção da confiabilidade do método, bem como salientaram a importância de utilizar profissionais com domínio técnico sobre o método e acompanhamento contínuo para identificar possíveis falhas e corrigi-las a tempo. 
Ao abordar os sistemas de custeio por absorção, variável, padrão e o método UEP de forma comparativa, Malaquias et al. (2007) descreveram a existência de algumas semelhanças entre o custeio por absorção e o método das UEP's, citando a subjetividade. Referindo-se ao custeio por absorção, alegaram que a subjetividade advém da possibilidade de escolha do método de rateio dos custos, a fim de obter menor grau de arbitrariedade. Quanto ao caso do método UEP, registram que a subjetividade recai sobre a escolha do produto-base.

Em que pese diversos argumentos na literatura quanto aos benefícios do GP-UVA, Meyssonnier (2003) buscou identificar se este método de custeio poderia ser utilizado como ferramenta de gestão empresarial. Para considerar tal metodologia limitada e questionável em termos gerenciais, destacou aspectos como a subjetividade da escolha do produto-base (por não haver critérios específicos) e a necessidade de atualizações constantes como pontos desfavoráveis associados.

Por seu turno, De La Villarmois e Levant (2011) centraram atenções nos processos envolvidos na implantação do método UVA no período de 1995 a 2009. Nesse contexto, dessumiram como pontos positivos os aspectos acerca do rateio adequado dos custos, pouco dispêndio de recursos para implantação e que o método é adotado principalmente por pequenas empresas como estratégia defensiva.

Wernke, Junges e Lembeck (2015) realizaram um comparativo entre os métodos UEP e TDABC, visto que ambos baseiam-se no tempo de produção para a alocação dos custos indiretos. Nesse caso, mesmo com certa similaridade entre os métodos, os resultados demonstraram-se divergentes quanto ao custo unitário e total dos produtos, bem como foram encontradas diferenças entre os valores monetários atribuídos às capacidades utilizadas e ociosas dos postos operativos ou setores produtivos.

Fundamentando-se na necessidade a analisar a robustez do "Princípio das Relações Constantes", que sustenta os métodos de custeio baseados em equivalência (GP, UP/UVA e UEP), Ferrari e Reis (2016) fizeram um estudo bibliográfico no qual apresentaram uma discussão acerca dos fundamentos teóricos dos métodos. Como conclusão, apontaram a instabilidade das relações constantes como um fator que pode afetar a veracidade do princípio e argumentaram que este princípio, na verdade, deveria ser caracterizado apenas como um axioma ou postulado.

Por último, com o objetivo de verificar se o método UEP é adequado para utilização em uma empresa prestadora de serviços, Wernke, Lembeck e Junges (2017) aplicaram o método UEP em uma lavanderia de pequeno porte. Como achados do estudo salientaram os aspectos de que o método é compatível para empresas prestadoras de serviços que possuem suas atividades ligadas ao fator "tempo de produção" e que a qualidade das informações oriundas deste método está calcada na confiabilidade do tempo de passagem dos produtos/serviços pelos postos operativos. 
Como visto, não foram identificadas pesquisas que discorressem especificamente sobre o tema central deste artigo, o que se constitui uma lacuna de pesquisa que merece ser melhor explorada.

\section{Procedimentos metodológicos}

Esta pesquisa classifica-se como descritiva, qualitativa e estudo de caso. A pesquisa descritiva visa registrar, descrever e analisar as características de uma determinada população ou fenômeno, bem como constatar possíveis relações entre determinadas variáveis (Marconi \& Lakatos, 2011; Gil, 2017).

Quanto à natureza dos dados, a pesquisa assume caráter qualitativo porque pretende analisar se a escolha do produto-base no método de custeio UEP influencia no valor final do custo unitário dos produtos. Pesquisas com essa característica preocupam-se em analisar e interpretar aspectos mais profundos e descrever a complexidade de determinado problema, além de fornecer uma análise mais detalhada sobre as investigações, hábitos, atitudes, tendências de comportamento etc. (Marconi \& Lakatos, 2011; Sampieri, Collado, \& Lúcio, 2013).

No que concerne aos procedimentos, refere-se a um estudo de caso, pois enseja a produção de conhecimento de matéria específica. Nesse sentido, um estudo de caso consiste em aprofundar o conhecimento acerca de um problema não suficientemente definido, visando estimular a compreensão, sugerir hipóteses e questões ou desenvolver a teoria, explorar ou descrever acontecimentos (Yin, 2015).

Quanto à escolha da empresa objeto do estudo, esta ocorreu pelo critério de acessibilidade, visto que os gestores facultaram o acesso dos pesquisadores aos dados necessários. Nessa direção, a coleta de dados ocorreu no período de julho a agosto de 2018, obtendo-se os dados relativos ao mês de junho do mesmo ano. Assim, com o fito de coligir os dados foi inicialmente empregada a técnica de conversas informais com o gestor da entidade e com o contador, sendo que posteriormente passou-se a realizar a análise documental coletando dados mais específicos nos controles internos e na contabilidade da indústria pesquisada.

\section{Apresentação de análise dos resultados}

Nesta parte do artigo é realizada a caracterização da empresa estudada, são apresentados os dados coligidos e evidenciados os principais aspectos que alicerçaram os achados do estudo. 


\subsection{Caracterização da empresa estudada}

A pesquisa foi realizada uma linha de produção de frigorífico que produz principalmente alimentos embutidos (mortadelas, presuntos, salsichas etc.) e que está sediado em cidade do litoral sul de Santa Catarina. Por solicitação dos gestores foi omitida a identificação da empresa e da marca que a mesma utiliza, visando preservar informações comerciais. À época do estudo, a parte fabril contava com 98 funcionários, enquanto que outros 14 trabalhavam nos demais setores da firma.

\subsection{Aplicação do método UEP}

Para possibilitar uma conclusão a respeito do pressuposto desta pesquisa (ou seja, se a escolha do produto-base interfere ou não no custo unitário dos produtos), primeiramente foi necessário realizar o levantamento dos dados e seguir as etapas de implantação do método UEP, como deslindado na sequência.

\subsubsection{Divisão da fábrica em postos operativos}

Como a empresa pesquisada já utilizava uma planilha de custos baseada no método UEP, o trabalho dos pesquisadores foi facilitado. Nesse sentido, a parte industrial da companhia estava subdividida em seis setores fabris (abate, desossa, salsicharia, cozimento, fatiação e embalagem). Contudo, para o objetivo visado bastou utilizar uma destas unidades industriais, o que motivou a escolha da salsicharia como o foco priorizado neste estudo, sendo que esta unidade fabril estava dividida em nove postos operativos: (1) Triturador, (2) Moagem, (3) Pesagem, (4) Misturador, (5) Embutidora/grampeadora, (6) Embutidora/amarradora, (7) Emulsificador, (8) Preparo do tempero e (9) Pesar/empacotar.

\subsubsection{Custo por hora nos postos operativos}

A partir da definição dos postos operativos, a metodologia de implantação do método UEP requer o cálculo do custo/hora de cada um destes. No caso em lume, os valores obtidos da planilha de custos do frigorífico pesquisado estão sintetizados na Tabela 1. 
Tabela 1 - Custo/hora nos postos operativos (R\$)

\begin{tabular}{lr} 
Postos Operativos & Custo por hora (R\$) \\
\hline Triturador & 71,75 \\
Moagem & 84,65 \\
Pesagem & 37,58 \\
Misturador & 89,11 \\
Embut.-Gramp. & 138,49 \\
Embut.-Amar. & 287,13 \\
Emulsific. & 41,88 \\
Prep.Temp. & 50,39 \\
Pesar/Empac. & 87,35
\end{tabular}

Fonte: Elaborada pelos autores.

É pertinente esclarecer que os valores monetários utilizados como custos mensais abrangem gastos com folha de pagamento, depreciação das máquinas, energia elétrica da produção, manutenção do prédio fabril, depreciação predial e material de consumo, totalizando R\$ 171.981,48.

Assim, para apurar o custo por hora (R\$) de cada posto operativo primeiramente foi apurado o valor total alocado para cada posto operativo, cujo montante foi dividido pelo expediente mensal (em horas) para apurar o custo/hora respectivo. Por exemplo: o posto operativo "Triturador" teve custo mensal de $\mathrm{R} \$ 13.891,50$ e o número de horas de trabalho disponíveis no mês foi de 193,60 horas, o que acarretou custo/hora de $\mathrm{R} \$ 71,75$.

\subsubsection{Tempo de passagem dos produtos pelos POs}

O método UEP requer que sejam determinados os tempos de passagem dos produtos fabricados pelos postos operativos. Porém, como o objetivo deste estudo é averiguar a influência ou não da escolha do produto-base no custo final unitário dos produtos, foram selecionados dois produtos a fim de efetuar a comparação dos resultados entre estes.

Convém salientar, ainda, que o processamento das matérias-primas neste setor não era contínuo/ininterrupto, de vez que ocorriam paralisações programadas (para manutenção preventiva, por exemplo) ou eventuais (em virtude de quedas de energia, de reposição de peças danificadas etc.). Portanto, para calcular o esforço de produção com base no tempo de passagem de cada item nos postos operativos considerando as possíveis interrupções, o gestor industrial informou que os cálculos dos tempos de produção por hora levaram em conta a quantidade média diária produzida de cada produto.

No caso dos dois produtos escolhidos, os tempos de passagem respectivos estão expostos na Tabela 2. 
Tabela 2 - Tempo de passagem dos produtos

\begin{tabular}{lrr}
$\begin{array}{l}\text { Postos } \\
\text { Operativos }\end{array}$ & $\begin{array}{r}\text { Apresunt.-1048 } \\
\text { (Horas/unid.) }\end{array}$ & $\begin{array}{r}\text { Linguiça-10406 } \\
\text { (Horas/unid.) }\end{array}$ \\
\hline Triturador & 0,000313 & 0,000455 \\
Moagem & 0,000476 & 0,000455 \\
Pesagem & 0,000238 & 0,000244 \\
Misturador & 0,000278 & 0,000313 \\
Embut.-Gramp. & 0,000455 & - \\
Embut.-Amar. & 0,000556 & - \\
Emulsific. & 0,000833 & - \\
Prep.Temp. & 0,000313 & 0,000333 \\
Pesar/Empac. & 0,000385 & 0,000455
\end{tabular}

Fonte: Elaborada pelos autores.

A escolha destes dois produtos ocorreu por dois motivos: no caso do "Apresunt-1048.", este foi selecionado porque era o produto mais fabricado no setor escolhido; enquanto que o "Linguiça10406" foi considerado em virtude de se ser de uma linha diferente do outro produto (linguiças versus apresuntados).

Além disso, como pode ser visualizado na Tabela 2, os dois produtos têm tempos de passagens bastante distintos e percorrem quantidades diferentes de postos operativos para serem fabricados. Estas características díspares também foram consideradas quando da escolha destes, pois robustecem os achados do estudo quando a comparação leva em conta duas configurações de produtos bastante divergentes em termos dos esforços de produção consumidos.

\subsubsection{Determinação do produto-base e cálculo do valor do custo-base (R\$)}

Depois de definido o custo/hora de cada posto operativo, apurado o tempo de passagem dos produtos nas etapas fabris e escolhido o produto-base é possível calcular o custo do produto-base, que fundamenta os demais cálculos nas fases posteriores do método UEP.

Contudo, na literatura sugere-se que a escolha do produto-base deveria recair no produto de maior representatividade na produção ou naquele que passa por maior número de postos operativos. Em virtude disso, tal indefinição costuma ser aventada como um aspecto que acrescenta subjetividade a esta metodologia de custeamento (conforme comentado em seção precedente).

Assim, em decorrência do objetivo ora proposto, na Tabela 3 são apresentados os cálculos do custo do produto-base para os dois produtos escolhidos para fazer a comparação dos resultados finais em termos do custo fabril unitário. 
Moterle, S., Wernke, R., \& Zanin, A. (2020, out./dez.). Influência da escolha do produto-base do método Unidades de Esforço de Produção (UEP) no custo unitário de transformação

Tabela 3 - Custo do produto-base para as duas opções de produtos

\begin{tabular}{lcrrrr}
\hline & & \multicolumn{2}{c}{ Apresunt.-1048 } & \multicolumn{2}{c}{ Linguiça-10406 } \\
$\begin{array}{l}\text { Postos } \\
\text { Operativos }\end{array}$ & $\begin{array}{l}\text { a) Custo por hora } \\
\text { (R\$) }\end{array}$ & $\begin{array}{l}\text { b) Tempo de } \\
\text { passagem (h) }\end{array}$ & $\begin{array}{r}\text { c=aXb) Custo do } \\
\text { Prod.-base (R\$) }\end{array}$ & $\begin{array}{r}\text { b) Tempo de } \\
\text { passagem (h) }\end{array}$ & $\begin{array}{c}\text { c=aXb) Custo do } \\
\text { Prod.-base (R\$) }\end{array}$ \\
\hline Triturador & 71,75 & 0,000313 & 0,022423 & 0,000455 & 0,032615 \\
Moagem & 84,65 & 0,000476 & 0,040309 & 0,000455 & 0,038477 \\
Pesagem & 37,58 & 0,000238 & 0,008947 & 0,000244 & 0,009165 \\
Misturador & 89,11 & 0,000278 & 0,024754 & 0,000313 & 0,027848 \\
Embut.-Gramp. & 138,49 & 0,000455 & 0,062951 & - & - \\
Embut.-Amar. & 287,13 & 0,000556 & 0,159515 & - & - \\
Emulsific. & 41,88 & 0,000833 & 0,034903 & - & - \\
Prep.Temp. & 50,39 & 0,000313 & 0,015746 & 0,000333 & 0,016795 \\
Pesar/Empac. & 87,35 & 0,000385 & 0,033596 & 0,000455 & 0,039704 \\
Totais & - & - & 0,403144 & - & 0,164606 \\
\hline
\end{tabular}

Fonte: Elaborada pelos autores.

O cálculo utilizado para apurar do custo do produto-base (R\$়) consiste na multiplicação do custo/hora (R\$) do posto operativo pelo tempo de passagem (em horas) do produto naquela etapa fabril. Em seguida, é necessário somar todos os valores encontrados em cada posto operativo, onde para o produto "Apresunt.-1048" chegou-se ao custo de R\$ 0,403144 e para o produto "Linguiça10406 " R\$ 0,164606, cujos valores serão utilizados na fase posterior, conforme descrito na próxima seção.

\subsubsection{Cálculo do potencial produtivo}

Esta parte do método UEP tem a finalidade de calcular a capacidade horária de produção da indústria nos postos operativos, cuja nomenclatura adotada nesta metodologia é a do "potencial produtivo". Referido procedimento de cálculo está delineado de forma detalhada na Tabela 4.

Tabela 4 - Potencial produtivo (UEPs por hora)

\begin{tabular}{lcrrrr}
\hline & & \multicolumn{2}{c}{ Apresunt.-1048 } & \multicolumn{2}{c}{ Linguiça-10406 } \\
Postos & a) Custo por hora & 2) Custo do & 3=a/2) Potenc. & 2) Custo do & 3=a/2) Potenc. \\
Operativos & (R\$) & prod.-base (R\$) & Produt.(UEP/h) & prod.-base (R\$) & Produt.(UEP/h) \\
\hline Triturador & 71,75 & 0,403144 & 177,985041 & 0,164606 & 435,912030 \\
Moagem & 84,65 & 0,403144 & 209,973441 & 0,164606 & 514,256414 \\
Pesagem & 37,58 & 0,403144 & 93,211082 & 0,164606 & 228,287905 \\
Misturador & 89,11 & 0,403144 & 221,049701 & 0,164606 & 541,383833 \\
Embut.-Gramp. & 138,49 & 0,403144 & 343,530908 & 0,164606 & 841,358658 \\
Embut.-Amar. & 287,13 & 0,403144 & 712,220366 & 0,164606 & $1.744,334377$ \\
Emulsific. & 41,88 & 0,403144 & 103,891212 & 0,164606 & 254,445143 \\
Prep.Temp. & 50,39 & 0,403144 & 124,982393 & 0,164606 & 306,100604 \\
Pesar/Empac. & 87,35 & 0,403144 & 216,671289 & 0,164606 & 530,660446 \\
\hline
\end{tabular}

Fonte: Elaborada pelos autores.

A Tabela 4 evidencia que para conhecer a capacidade instalada de produção em UEPs se faz a divisão do custo/hora (R\$̦) de cada posto operativo pelo custo do produto-base. Por exemplo: no caso do "Apresunt-1048", considerando que a etapa "Triturador" custou R\$ 71,75 por hora, este valor foi 
dividido pelo custo do respectivo produto-base de $\mathrm{R} \$$ 0,403144 (apurado na Tabela 3 da seção anterior). Com isso, o potencial produtivo calculado foi de 177,985041 UEPs por hora.

Procedimento semelhante foi realizado para os demais postos operativos e também para o segundo produto (Linguiça-10406) e permitiu concluir que há diferentes capacidades de produção ao longo dos nove postos operativos pelos quais os produtos podem (ou não) passar. Essa disparidade de capacidades instaladas dos postos operativos indica a existência de "gargalos", o que merece uma atenção especial dos gestores para aprimorar esse fluxo produtivo.

\subsubsection{Cálculo dos equivalentes de produção em UEPS}

Para determinar os equivalentes de produção em UEPs dos produtos, basta multiplicar (individualmente) o (i) tempo de passagem do produto pelos postos operativos necessários para sua elaboração pelo (ii) potencial produtivo em UEPs/hora de cada "PO". Nesse rumo, no caso dos dois produtos utilizados para comparar os resultados, os cálculos a respeito estão representados a seguir.

Primeiramente foram feitos os cálculos que consideram o produto "Apresunt-1048." como o produto-base e o outro item como um produto secundário, como consta da Tabela 5.

Tabela 5 - Equivalentes em UEP com prod.-base "Apresunt.1048"

\begin{tabular}{|c|c|c|c|}
\hline \multicolumn{4}{|c|}{ Produto-base: Apresunt.-1048 } \\
\hline Postos & b) Tempo de & 3) Potencial & 4=bX3) Equival. \\
\hline Operativos & passagem (h) & Produtivo (UEP/h) & em UEP \\
\hline Triturador & 0,000313 & 177,985041 & 0,0556203 \\
\hline Moagem & 0,000476 & 209,973441 & 0,0999874 \\
\hline Pesagem & 0,000238 & 93,211082 & 0,0221931 \\
\hline Misturador & 0,000278 & 221,049701 & 0,0614027 \\
\hline Embut.-Gramp. & 0,000455 & 343,530908 & 0,1561504 \\
\hline Embut.-Amar. & 0,000556 & 712,220366 & 0,3956780 \\
\hline Emulsific. & 0,000833 & 103,891212 & 0,0865760 \\
\hline Prep.Temp. & 0,000313 & 124,982393 & 0,0390570 \\
\hline Pesar/Empac. & 0,000385 & 216,671289 & 0,0833351 \\
\hline Total & - & - & 1,0000000 \\
\hline \multicolumn{4}{|c|}{ Linguiça-10406 } \\
\hline Postos & b) Tempo de & 3) Potencial & 4=bX3) Equival. \\
\hline Operativos & passagem (h) & Produtivo (UEP/h) & em UEP \\
\hline Triturador & 0,0004545 & 177,9850408 & 0,0809023 \\
\hline Moagem & 0,0004545 & 209,9734409 & 0,0954425 \\
\hline Pesagem & 0,0002439 & 93,2110823 & 0,0227344 \\
\hline Misturador & 0,0003125 & 221,0497007 & 0,0690780 \\
\hline Embut.-Gramp. & - & 343,5309075 & - \\
\hline Embut.-Amar. & - & 712,2203658 & - \\
\hline Emulsific. & - & 103,8912123 & - \\
\hline Prep.Temp. & 0,0003333 & 124,9823927 & 0,0416608 \\
\hline Pesar/Empac. & 0,0004545 & 216,6712885 & 0,0984869 \\
\hline Total & - & & 0,4083050 \\
\hline
\end{tabular}

Fonte: Elaborada pelos autores. 
Moterle, S., Wernke, R., \& Zanin, A. (2020, out./dez.). Influência da escolha do produto-base do método Unidades de Esforço de Produção (UEP) no custo unitário de transformação

Como expresso na Tabela 5, a determinação do equivalente em UEP de cada produto (última coluna à direita) requer a multiplicação do "b) Tempo de passagem (h)" pelo "3) Potencial produtivo (UEP/h)" e a posterior soma destes resultados em todos os postos operativos.

Destarte, ao considerar o "Apresunt-1048." como produto-base, este totalizou 1,000000 UEP, enquanto que o "Linguiça-10406" chegou a 0,4083050 UEP. Essa paridade entre ambos permite concluir que o segundo produto despende somente cerca de $40,83 \%$ dos esforços requeridos para fabricar o "Apresunt-1048.".

Entretanto, quando o produto-base passa a ser o "Linguiça-10406", os valores relativos aos respectivos equivalentes em UEPs dos dois produtos priorizados são modificados, conforme demonstrado na Tabela 6.

Tabela 6 - Equivalentes em UEP com prod.-base "Linguiça-10406"

Produto-base: Linguiça-10406

\begin{tabular}{|c|c|c|c|}
\hline $\begin{array}{l}\text { Postos } \\
\text { Operativos }\end{array}$ & $\begin{array}{l}\text { b) Tempo de } \\
\text { passagem (h) }\end{array}$ & $\begin{array}{c}\text { 3) Potencial } \\
\text { Produtivo (UEP/h) }\end{array}$ & $\begin{array}{c}\text { 4=bX3) Equival. } \\
\text { em UEP }\end{array}$ \\
\hline Triturador & 0,00045455 & 435,91202962 & 0,1981418 \\
\hline Moagem & 0,00045455 & 514,25641380 & 0,2337529 \\
\hline Pesagem & 0,00024390 & 228,28790490 & 0,0556800 \\
\hline Misturador & 0,00031250 & 541,38383331 & 0,1691824 \\
\hline Embut.-Gramp. & - & 841,35865839 & - \\
\hline Embut.-Amar. & - & $1.744,33437673$ & - \\
\hline Emulsific. & - & 254,44514328 & 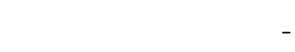 \\
\hline Prep.Temp. & 0,00033333 & 306,10060393 & 0,1020335 \\
\hline Pesar/Empac. & 0,00045455 & 530,66044599 & 0,2412093 \\
\hline Total & - & - & 1,0000000 \\
\hline \multicolumn{4}{|c|}{ Apresunt.-1048 } \\
\hline $\begin{array}{l}\text { Postos } \\
\text { Operativos }\end{array}$ & $\begin{array}{l}\text { b) Tempo de } \\
\text { passagem (h) }\end{array}$ & $\begin{array}{l}\text { 3) Potencial } \\
\text { Produtivo (UEP/h) }\end{array}$ & $\begin{array}{c}\text { 4=bX3) Equival. } \\
\text { em UEP }\end{array}$ \\
\hline Triturador & 0,00031250 & 435,91202962 & 0,1362225 \\
\hline Moagem & 0,00047619 & 514,25641380 & 0,2448840 \\
\hline Pesagem & 0,00023810 & 228,28790490 & 0,0543543 \\
\hline Misturador & 0,00027778 & 541,38383331 & 0,1503844 \\
\hline Embut.-Gramp. & 0,00045455 & 841,35865839 & 0,3824358 \\
\hline Embut.-Amar. & 0,00055556 & $1.744,33437673$ & 0,9690747 \\
\hline Emulsific. & 0,00083333 & 254,44514328 & 0,2120376 \\
\hline Prep.Temp. & 0,00031250 & 306,10060393 & 0,0956564 \\
\hline Pesar/Empac. & 0,00038462 & 530,66044599 & 0,2041002 \\
\hline Total & - & - & 2,4491498 \\
\hline
\end{tabular}

Fonte: Elaborada pelos autores.

Com base nos resultados dos cálculos mencionados na Tabela 6 se constata que o produto "Linguiça-10406" passou a valer 1,000000 UEP, enquanto que para o "Apresunt-1048." foi atribuído o valor equivalente a 2,4491498 UEPs. Por esse prisma, cabe considerar que este último produto é 144,91\% mais caro para ser fabricado se comparado com o "Linguiça-10406". 


\subsubsection{Produção de UEPs no período}

A definição dos equivalentes dos produtos em UEPs permite calcular a produção total mensal em termos desta unidade fabril. Então, para o prosseguimento da comparação ora desejada entre os dois produtos, na Tabela 7 estão demonstrados os cálculos realizados considerando estas duas possibilidades de escolha do produto-base.

Tabela 7- Produção de UEPS no período nas duas opções

\begin{tabular}{lrrr}
\hline \multicolumn{3}{c}{ Produto-base: Apresunt.1048 } \\
\hline Produtos & $\begin{array}{r}\text { 1) Quantidade } \\
\text { Produzida }\end{array}$ & $\begin{array}{r}\text { 2) } \\
\text { Equivalente } \\
\text { em UEPs }\end{array}$ & $\begin{array}{r}\text { 3=1x2) Produção } \\
\text { de UEPs no mês }\end{array}$ \\
\hline Apresunt.-1048 & 20.350 & 1,000000 & $20.350,00$ \\
Linguiça-10406 & 23.460 & 0,367404 & $8.619,30$ \\
Outros & 342.560 & - & $186.261,92$ \\
Totais & 386.370 & - & $215.231,22$ \\
\hline & Produto-base: Linguiça-10406 & $3=1 \times 2)$ Produção \\
\hline \multirow{2}{*}{ Produtos } & 1) Quantidade & 2) Equivalente & de UEPs no mês \\
\hline Apresunt.-1048 & produzida & em UEPs & $55.388,58$ \\
Linguiça-10406 & 20.350 & 2,721797 & $23.460,00$ \\
Outros & 23.460 & 1,000000 & $506.967,20$ \\
Totais & 342.560 & - & $585.815,78$ \\
\hline
\end{tabular}

Fonte: Elaborada pelos autores.

É cabível destacar que o mix de produtos fabricados no mês da pesquisa implicou na produção de 386.370 unidades, conforme dados obtidos nos controles internos da produção da empresa em tela. Contudo, dos dois itens priorizados a produção foi de apenas 20.350 unidades do "Apresunt1048." e 23.460 unidades do "Linguiça-10406", sendo que os demais produtos estão agrupados na linha "Outros" da Tabela 7.

Quando considerado como produto-base o "Apresunt-1048." (parte superior da Tabela 7), o total de UEPs produzidas pela fábrica no período estudado foi 215.231,22. Deste total, 20.350 UEPs referem-se ao "Apresunt-1048." e 8.619,30 UEPs estão vinculadas ao "Linguiça-10406". Porém, quando visualizada a segunda parte da Tabela 7, na qual os cálculos foram realizados considerando como produto-base o "Linguiça-10406", os valores foram bastante diferentes e totalizaram 585.815,78 UEPs. No que concerne ao "Apresunt-1048.", a quantidade total de UEPs do mês deste chegou a 55.388,58 UEPs, enquanto que para o "Linguiça-10406" o volume de UEPs calculado atingiu 23.460 UEPS.

Esses volumes de UEPs fabricados no período são empregados para definir o valor monetário de cada UEP, conforme destacado na próxima seção. 
Moterle, S., Wernke, R., \& Zanin, A. (2020, out./dez.). Influência da escolha do produto-base do método Unidades de Esforço de Produção (UEP) no custo unitário de transformação

\subsubsection{Cálculo do valor da UEP}

Para determinar o valor unitário (R\$) da UEP é necessário dividir o (1) custo total de transformação do mês (R\$) pelo (2) total de UEPs produzidas no mesmo período. Nesse rumo, o referido procedimento de cálculo foi realizado para as duas opções de produto-base, nos moldes do retratado na Tabela 8.

Tabela 8 - Cálculo do valor unitário (em R\$) da UEP do mês

\begin{tabular}{lrr}
\hline Itens & Prod.-base: Apresunt.1048 & Prod.-base: Linguiça-10406 \\
\hline 1. Custo total de transformação do período - R\$ & $171.981,48$ & $171.981,48$ \\
2. Produção total de UEPs do período & $215.231,22$ & $585.815,78$ \\
$3=1 / 2$ ) Valor da UEP no período - R\$ & 0,799055 & 0,293576 \\
\hline
\end{tabular}

Fonte: Elaborada pelos autores.

Os valores da última linha da Tabela 8 demonstram que ao dividir o (1) custo total de transformação do mês (R\$ 171.981,48) pelo (2) volume total de UEPs fabricadas (que se altera conforme o produto que atua como produto-base), o $(3=1 / 2)$ valor do custo unitário da UEP é alterado.

Esses resultados diferentes (R\$ 0,799055 versus $\mathrm{R} \$ 0,293576$ ) conforme o produto utilizado como referência nos cálculos da UEP são aceitáveis se considerar o fato de que o custo total de transformação foi de R\$ 171.981,48 no mês da pesquisa e os volumes de UEPs são distintos nos dois contextos (215.231,22 quando o produto-base é o "Apresunt-1048." contra 585.815,78 se considerado o "Linguiça-10406").

\subsubsection{Custo unitário de transformação dos produtos}

Os dados apurados por intermédio dos cálculos comentados nas seções anteriores subsidiam o cálculo do custo unitário de transformação dos produtos, o que permite a resolução do problema de pesquisa, conforme descrito na Tabela 9.

Tabela 9 - Custo unitário de transformação dos produtos (em R\$়)

\begin{tabular}{|c|c|c|c|}
\hline \multicolumn{4}{|c|}{ Produto-base: Apresunt.1048 } \\
\hline Produtos & $\begin{array}{l}\text { 1) Equivalente em } \\
\text { UEP do produto }\end{array}$ & $\begin{array}{r}\text { 2) Valor da UEP } \\
\text { no mês - R\$ }\end{array}$ & $\begin{array}{l}3=1 \times 2) \text { Custo unit. De } \\
\text { transformação }-\mathrm{R} \$\end{array}$ \\
\hline Apresunt.-1048 & 1,000000 & 0,799055 & 0,799055 \\
\hline Linguiça-10406 & 0,367404 & 0,799055 & 0,293576 \\
\hline \multicolumn{4}{|c|}{ Produto-base: Linguiça-10406 } \\
\hline Produtos & $\begin{array}{l}\text { 1) Equivalente em } \\
\text { UEP do produto }\end{array}$ & $\begin{array}{r}\text { 2) Valor da UEP } \\
\text { no mês - R\$ }\end{array}$ & $\begin{array}{l}3=1 \times 2) \text { Custo unit. De } \\
\text { transformação }-\mathrm{R} \$\end{array}$ \\
\hline Apresunt.-1048 & 2,721797 & 0,293576 & 0,799055 \\
\hline Linguiça-10406 & 1,000000 & 0,293576 & 0,293576 \\
\hline
\end{tabular}

Fonte: Elaborada pelos autores.

Ao ser utilizado como produto-base o "Apresunt-1048." (como especificado na metade superior da Tabela 9) o custo unitário de transformação deste item foi de $\mathrm{R} \$$ 0,799055 e o custo do 
"Linguiça-10406" foi de $\mathrm{R} \$$ 0,293576. Para chegar a esses valores foram multiplicados os respectivos equivalentes em UEP dos dois produtos pelo valor da UEP no mês da pesquisa (R\$ 0,799055).

Todavia, se considerado como produto-base o "Linguiça-10406" (metade inferior da Tabela 9), mesmo que o valor da UEP no mês tenha passado para R\$ 0,293576 e os equivalentes em UEP calculados tenham sido de "1,0000000" para o mencionado produto e "2,721797" para o "Apresunt1048.", o valor do custo unitário dos dois produtos permaneceu igual à situação do parágrafo anterior, ou seja, $\mathrm{R} \$$ 0,799055 e R\$ 0,293576 respectivamente para os produtos "Apresunt-1048" e "Linguiça$1046^{\prime \prime}$.

\subsection{Discussão dos resultados e cotejamento com estudos anteriores}

Os cálculos evidenciados nas seções precedentes permitem destacar alguns aspectos considerados de maior relevância nesta pesquisa.

A implantação do Método UEP para custeamento fabril é de certa forma moroso, visto que se faz necessário o levantamento de uma série de dados. No entanto, uma vez que é realizada a coleta das informações, a operacionalização e manutenção tornam-se mais simples, bastando a alimentação das planilhas mensalmente e atualizações diante de alterações no processo produtivo consideradas relevantes.

Conforme exposto na revisão da literatura, uma das preocupações debatidas por pesquisadores sobre os métodos de custeio que usam a equivalência de produtos diz respeito à escolha do produto-base, que para alguns estudiosos justifica a atribuição de uma certa dose de subjetividade ao método. A partir dessa constatação é que surgiu a questão que se pretendeu responder, ou seja, se a escolha do produto-base do método UEP efetivamente influencia no valor monetário do custo unitário de transformação dos produtos. Assim, os autores deste estudo buscaram esclarecer tal dúvida por meio do cálculo dos custos unitários (em $R \$$ ) dos integrantes do mix produzido por uma fábrica com duas opções de produto-base.

Pelos resultados expostos na seção precedente (vide Tabela 9) foi constatado que, independentemente do produto-base considerado nos cálculos, o custo unitário de transformação dos produtos permaneceu idêntico: R\$ 0,799055 para o "Apresunt-1048." e R\$ 0,293576 para o "Linguiça-10406". Portanto, é cabível asseverar que a escolha do produto-base não deve ser considerada uma fragilidade do método UEP, pois não influencia no valor final a ser alocado aos produtos como custo unitário de transformação destes.

Nesse rumo, com fulcro na conclusão citada, dessume-se que os achados desta pesquisa divergem dos argumentos apontados em estudos anteriores que enfatizavam a presença de subjetividade no método UEP (e provavelmente de outros baseados na equivalência de produtos) em virtude da ausência de um critério específico para definir o produto de referência (Meyssonnier, 2003; 
Malaquias et al., 2007; Pereira, 2015). Cabe ressaltar, ainda, que embora essa subjetividade seja uma inconsistência comumente atribuída a este método, não foram encontradas publicações que justificassem tal opinião desfavorável. Ou seja, há comentários a respeito desse aspecto tido como negativo, mas nenhum artigo tratou de comprovar ou refutar se essa alegada deficiência teria algum impacto nos valores de custos dos produtos.

Em sentido oposto, ao atestar que a seleção do produto-base é indiferente em termos do resultado final do custo unitário dos produtos, esta pesquisa corrobora o posicionamento de Wernke e Junges (2017). Embora tal estudo não tenha discorrido de forma a comprovar matematicamente a respeito desse assunto, tais autores registraram que a alteração do produto-base não teria o condão de afetar o valor do custo unitário alocado aos produtos.

\section{Considerações finais}

A subjetividade citada na literatura de custos quanto à escolha do produto-base pode ser qualificada como uma desvantagem do método UEP ou uma restrição a sua implantação, pois os gestores fabris podem considerar que tal método não teria condições de proporcionar resultados confiáveis a partir dessa característica.

A partir desse contexto, este estudo objetivou analisar se a escolha do produto-base do método UEP influenciaria o valor monetário do custo unitário dos produtos em uma indústria de alimentos embutidos. Nessa direção, considera-se que tal objetivo foi atingido porque os resultados deslindados na Tabela 9 comprovaram que, independentemente do produto-base escolhido, não há alteração no valor final alocado a cada produto em termos de custo unitário de transformação.

Nesse ponto reside o busílis deste estudo, visto que foi elucidada uma questão que vinha sendo constantemente ventilada nas publicações acerca do Método UEP e de outros com concepção assemelhada. Portanto, a contribuição principal desta pesquisa reside no fato de comprovar, matematicamente, que não cabe considerar como um aspecto negativo a ausência de critério(s) específico(s) para definir qual item deve ser escolhido como produto-base. Além disso, dirimiu-se por completo a dúvida suscitada na pergunta que embasou esta investigação.

No que concerne às limitações associáveis a esta pesquisa, por tratar-se de um estudo de caso as suas conclusões deveriam ser circunscritas ao âmbito da empresa em tela, evitando-se generalizações a respeito. Contudo, os autores consideram que os procedimentos de cálculos relatados em detalhes nas tabelas expostas nas seções anteriores permitem que tal experimento possa ser replicado facilmente em outros tipos ou portes de empresas fabris. Assim, aproveita-se essa possibilidade para recomendar que outras pesquisas sejam realizadas com o mesmo enfoque, o que pode fornecer mais robustez aos achados deste estudo. 


\section{Referências}

Allora, F., \& Allora, V. (1995). UP: unidade de medida da produção. São Paulo: Pioneira.

Allora, V., \& Gantzel, G. (1996). Revolução nos custos: os métodos ABC e UP e a gestão estratégica de custos como ferramenta para a competitividade. Salvador: Casa da Qualidade.

Allora, V., \& Oliveira, S. E. (2010) Gestão de custos: metodologia para a melhoria da performance empresarial. Curitiba: Juruá.

Bornia, A. C. (2009). Análise gerencial de custos: aplicação em empresas modernas. 2a. ed. São Paulo: Atlas.

Datar, S., \& Gupta, M. (1994). Aggregation, specification and measurement errors in product costing. Accounting Review, 69(4), 567-591.

De La Villarmois, O., \& Levant, Y. (2005). La mise en place et I'utilisation d'une méthode d'évaluation des coûts: le cas de la méthode UVA. Finance Contrôle Stratégie, 8(2), 175-205.

De La Villarmois, O., \& Levant, Y. (2011). From adoption to use of a management control tool: case study evidence of a costing method. Journal of Applied Accounting Research, 12(3), 234-259.

Ferrari, M. J., \& Reis, L. S. (2016). Princípios na gestão de custos: uma reflexão teórica acerca dos fundamentos epistemológicos dos modelos de equivalência. In: Congresso Brasileiro de Custos, 23. 2016, Porto de Galinhas. Anais... Porto de Galinhas: ABC.

Gervais, M. Contrôle de gestion. (2009). 9ạ ed. Economica: Paris.

Gervais, M., \& Levant, Y. (2007). Comment garantir l'homogénéité globale dans la méthode UVA? Deux études de cas. Revue Finance Contrôle Stratégie, 10(3), 43-73.

Gil, A. C. (2017). Como elaborar projetos de pesquisa. 5a ed. São Paulo: Atlas.

Guimarães Filho, L. P., Bristot, V. M., Marques, L. D. R., Feil, N. F., \& Colombo, T. C. (2016). Aplicação do método UEP na determinação dos custos de uma empresa de revestimentos cerâmicos. ABCustos, 11(3), 28-59.

Kaplan, R. S., \& Anderson, S. R. (2004). Time-Driven Activity-Based Costing. Harvard Business Review, 82(11), 131-138.

Levant, Y., \& Zimnovitch, H. (2013). Contemporary evolutions in costing methods: understanding these trends through the use of equivalence methods in France. Accounting History, 18(1), 51-75.

Lopes, I. F., \& Beuren, I. M. (2017). Comportamento dos custos e sua relação com medidas de eficiência operacional em companhias aéreas. Revista Base (Administração e Contabilidade) da UNISINOS, 14(1), 30-46.

Lunkes, R. J., Luiz, G., Gasparetto, V., \& Schnorrenberger, D. (2015). Utilização do Método da Unidade de Esforço de Produção (UEP): estudo em uma empresa de cosméticos. ABCustos, 9(1), 29-47.

Malaquias, R. F., Giachero, O. S., Costa, B. E. da, \& Lemes, S. (2007). Método das unidades de esforço de produção versus métodos de custeio tradicionais: um contraponto. In: Congresso Brasileiro de Custos, 14, 2007, João Pessoa. Anais... João Pessoa: ABC/UFPB. 
Moterle, S., Wernke, R., \& Zanin, A. (2020, out./dez.). Influência da escolha do produto-base do método Unidades de Esforço de Produção (UEP) no custo unitário de transformação

Marconi, M. A., \& Lakatos, E. M. (2011). Metodologia do trabalho científico. 7ạ ed. São Paulo: Atlas.

Martins, E., \& Rocha, W. (2010). Métodos de custeio comparados: custos e margens analisadas sob diferentes perspectivas. São Paulo: Atlas.

Meyssonnier, F. L'approche des coûts complets par les équivalents de production, voie d'avenir ou impasse? (une analyse de la méthode GP-UVA). (2003). Comptabilité-Contrôle-Audit, France, 9(1), 111-124.

Pereira, S. I. M. (2015). Custeio por atividades (ABC) e unidade de esforço de produção (UEP): similaridades, diferenças e complementaridades. Dissertação (Mestrado). PPGCC da Universidade de São Paulo - USP.

Sampieri, R. H., Collado, C. F., \& Lúcio, M. P. B. (2013). Metodologia de pesquisa. 5a ed. Porto Alegre: Penso.

Souza, M. A., \& Diehl, C. A. (2009). Gestão de custos: uma abordagem integrada entre contabilidade, engenharia e administração. São Paulo: Atlas.

Wernke, R. (2019). Análise de custos e preços de venda: ênfase em aplicações e casos nacionais. 2aㅡ ed. São Paulo: Atlas.

Wernke, R., \& Junges, I. (2017). Impacto da ociosidade no valor do custo fabril unitário apurado pelo método UEP. Iberoamerican Journal of Industrial Engineering, 9(17), 138-161.

Wernke, R., \& Junges, I. (2017b). Indicadores não financeiros do Método UEP aplicáveis à gestão fabril de frigorífico. Custos e Agronegócios Online, 13(1), 66-104.

Wernke, R., Junges, I., \& Cláudio, D. A. (2013). Indicadores não financeiros do método UEP aplicáveis à gestão de pequena indústria. Iberoamerican Journal of Industrial Engineering, 4(8), 125-145.

Wernke, R., Junges, I., \& Lembeck, M. (2015). Comparativo entre os métodos UEP e TDABC: estudo de caso. Revista Ambiente Contábil, 7(1), 51-69.

Wernke, R., Lembeck, M., \& Junges, I. (2017). Método UEP aplicado em prestadora de serviços. Iberoamerican Journal of Industrial Engineering, 9(18), 112-137.

Wernke, R., Santos, A. P. dos, Junges, I., \& Scheren, G. (2018). Comparação do custo fabril apurado pelos métodos Unidades de Esforço de Produção (UEP) e Time-driven Activity-based Costing (TDABC): estudo de caso em linha de produção de frigorífico. Exacta, 16(3), 103-119.

Yin, R. K. (2015). Estudo de caso: planejamento e métodos. 5a ed. Porto Alegre: Bookman.

Recebido em: 09 out. 2018 / Aprovado em: 09 out. 2019

Para referenciar este texto

American Psychological Association (APA)

Moterle, S., Wernke, R., \& Zanin, A. (2020, out./dez.). Influência da escolha do produtobase do método Unidades de Esforço de Produção (UEP) no custo unitário de transformação. Exacta, 18(4), 758-777. https://doi.org/10.5585/exactaep.v18n4.10700. 